\title{
Locative expressions in signed languages: a view from Turkish Sign Language (TiD) ${ }^{1}$
}

\author{
ASLI ÖZYÜREK, INGE ZWITSERLOOD, AND PAMELA PERNISS
}

Abstract

Locative expressions encode the spatial relationship between two (or more) entities. In this paper, we focus on locative expressions in signed language, which use the visual-spatial modality for linguistic expression, specifically in Turkish Sign Language ( Türk İşaret Dili, henceforth TID). We show that TID uses various strategies in discourse to encode the relation between a Ground entity (i.e., a bigger and/or backgrounded entity) and a Figure entity (i.e., a smaller entity, which is in the focus of attention). Some of these strategies exploit affordances of the visual modality for analogue representation and support evidence for modality-specific effects on locative expressions in sign languages. However, other modality-specific strategies, e.g., the simultaneous expression of Figure and Ground, which have been reported for many other sign languages, occurs only sparsely in TID. Furthermore, TID uses categorical as well as analogical structures in locative expressions. On the basis of these findings, we discuss differences and similarities between signed and spoken languages to broaden our understanding of the range of structures used in natural language (i.e., in both the visual-spatial or oral-aural modalities) to encode locative relations. A general linguistic theory of spatial relations, and specifically of locative expressions, must take all structures that might arise in both modalities into account before it can generalize over the human language faculty.

\section{Introduction}

Locative expressions, in both spoken and signed languages, encode the spatial relationships between entities. This can be a Figure-Ground relation, in which one entity (i.e., a Figure) is situated in relation to another one (i.e., a Ground) (Talmy 1985). Conceptually, the Ground is considered to be the bigger and/or backgrounded entity, while the Figure is the smaller entity, which is in the 


\section{A. Özyürek et al.}

focus of attention. Relations between the Figure and the Ground can be encoded in different ways: the Figure can be at a certain location with respect to the Ground (e.g., in a relationship of containment, support, or proximity), as in topological descriptions like 'the cup is on the table' or 'the pen is next to the paper', or the Figure can be moving with respect to the Ground, as in motion descriptions like 'the cup fell from the table' or 'the man walked alongside the fence' (Levinson and Wilkins 2006). ${ }^{2}$

In this paper, we focus on how the encoding of Figure and Ground relations in locative expressions is manifested in a signed language, specifically in Turkish Sign Language (Türk Işsaret Dili, henceforth TID) — the main natural language of the Deaf community in Turkey. ${ }^{3}$ Furthermore, we will discuss differences and similarities between signed and spoken languages in this regard, to broaden the scope of our understanding of the structures used in natural languages to encode locative relations beyond the specific modality (i.e., visual-spatial or oral-aural) through which they are conveyed.

\section{Locative expressions in spoken languages}

Recent surveys of descriptive studies investigating the expression of spatial relations in different spoken languages show that there are multiple devices available to users of spoken languages to encode a locative semantic relation between Figure and Ground (Grinevald 2006; Levinson and Wilkins 2006). The types of devices used in the languages studied in these surveys can be grouped into a) adpositions, such as prepositions (e.g., in English, German and Dutch) or postpositions (e.g., case markers as in Turkish, Japanese and Finnish); and b) locative or postural verbs (e.g., in Ewe and Tzeltal). Some languages use mainly one type of device, while other languages use different devices that may appear in combination. We elaborate on these devices and provide examples from various languages below.

One adpositional strategy to encode a Figure-Ground relation is the use of spatial prepositions (e.g., 'on'), familiar from English, as illustrated in (1).

(1) English

The cup is on the table.

Another type of adpositions used to mark Figure-Ground relations are morphological case markers (usually occurring as postpositions). Case markers can be attached to the noun that indicates the Ground object. ${ }^{4}$ For example, in Turkish, a general locative case marker ( $-d a$ 'at') can be attached to the noun expressing the Ground object ( $2 \mathrm{a}$ ) or to a spatial noun accompanying the Ground noun (e.g., üst 'on top', alt 'under'), which conveys more specifically the nature of the relation between Figure and Ground (2b). ${ }^{5}$ 
(2) Turkish
a. Fincan masa-da
cup table-CASE:LOC
'The cup is on the table.' (lit. 'The cup is at the table.')
b. Fincan masa-nın üst-ün- de cup table-POSS top-CASE:GEN- CASE:LOC
'The cup is on the table.' (lit. 'The cup is on top of the table.')

Some spoken languages use locative verbs to encode relations between Figure and Ground. For example, Ewe encodes general locative relations in the verb le 'be.at' (in addition to case markers that appear on the Ground noun). This is illustrated in (3) (adapted from Ameka and Essegbey [2006]).

(3) Ewe
Asige le asi- ne
ring be.at hand-CASE:AT
'The ring is on his/her finger.'

It is also possible for a spoken language to encode locative relations mainly by posture verbs, which incorporate information about the posture of the Figure. In such cases the locative relation can be inferred by knowledge of the posture of the Figure and the nature of the Ground. An example from Tzeltal is given in (4) (cited in Grinevald [2006: 42]).

(4) Tzeltal

$\begin{array}{llll}\text { Waxal-ø } & t a \quad t i '- & k j k & \text { pin } \\ \text { Vertical-ABS3p PREP mouth- fire pot } \\ \text { 'The pot is standing vertical by the fire.' }\end{array}$

The combination of devices in spoken languages is quite common. In the examples above, we see how locative or positional verbs and (sometimes semantically empty) case markers are combined in locative expressions.

In the next section, we discuss the strategies available in signed languages, in general, and in TiD, in particular, to encode the relations between a Figure and a Ground. We then go on to discuss ways in which signed languages locative expressions might compare to the different types of encoding of spatial relations in spoken languages.

\section{Locative expressions in signed languages}

Signed and spoken languages differ in the main articulators used for linguistic expression. Signed languages are expressed in the manual-visual modality, in 
which the hands, body, face, mouth, and eyes function as articulators, whereas spoken languages primarily use the oral-aural channel. Furthermore, while in spoken languages expressions are mostly suited for linear information ordering, ${ }^{6}$ the visual modality of signed languages allows more simultaneous and three-dimensional spatial structuring of information than spoken languages as well as the use of the linear temporal dimension. In spite of these modality differences, signed languages have been found to share basic linguistic properties with spoken languages, at levels of phonology, morphology, and syntax (Klima and Bellugi 1979; Sandler and Lillo-Martin 2006). Signed languages of different countries have been shown to vary in terms of their vocabularies, form distinctions, syntax, and word order, as spoken languages do (Woll 2003; Perniss et al. 2007). Furthermore, similar neural structures have been found to support processing of both signed and spoken languages (Poizner et al. 1987; Emmorey 2002). These findings have led to the conclusion that some fundamental features of language are similar in both signed and spoken languages, independent of the modality of expression.

However, recent studies have shown that the structure of signed languages also shows modality-specific effects in some core domains of linguistic expression. Moreover, it is in these domains that many signed languages studied so far have been claimed to show similarities to each other (e.g., Meier et al. 2002; Woll 2003). One of these domains (in addition to the use of pronouns and verb agreement marking) is the expression of spatial relations. Due to the one-to-one schematic correspondence between the (visual) spatial relations expressed and the visual medium of expression (i.e., the "confluence of space and language"), spatial expressions in signed languages have been considered to be more visually motivated (or iconic) than their counterparts in spoken languages (Emmorey 1996, 2002). The visual-spatial modality makes it possible for signers to directly map the relative locations and motions of referents onto the hands and sign space. For example, in many signed languages a handshape with extended index and middle fingers pointing downwards $\left(\omega^{3}\right)$ and located in sign space, can express a person standing somewhere; the same handshape, with wiggling fingers, moving to or from a location, can express a person walking somewhere. This form is more visually motivated than the form of an expression in a spoken language, e.g., 'He is standing somewhere' or 'He is walking somewhere'.

The expression of locative relations between entities has been claimed to be similar across signed languages (Aronoff et al. 2005; Emmorey 2002; Meier 2002; Talmy 2003). These claims have been attributed to the homogenizing effect of the iconic (i.e., visually motivated) properties of signed languages, in contrast to spoken languages (Aronoff et al. 2005). However, these claims are based on research on a small set of signed languages and with almost no report of their frequency in use. Furthermore, the structure of the spatial 
expressions and the way in which they are used in discourse contexts have hardly been analyzed (but see Engberg-Pederson [1993]; Zwitserlood [2003]; and Perniss 2007 for exceptions). Research on more signed languages, including lesser-known ones, with more diverse data is necessary to test these claims.

Below we summarize findings based on previous research on signed languages, continuing with a discussion about the extent in which our research on TID, i.e., our analysis of locative expressions in discourse contexts, overlaps and differs from these findings.

\subsection{Previous findings: the canonical structure of locative expressions}

Sign language users can use the physical space around them to associate referents with locations and to indicate the relationships between them for expressions of both spatial and nonspatial content. In spatial descriptions, the creation of referent-location associations in sign space is argued to be motivated by the potential afforded by the visual-spatial modality of mapping spatial relations onto sign space in an analogue way (e.g., Emmorey 2002; Talmy 2003). Furthermore, the initial similarities noticed between signed languages in the domain of spatial descriptions have led to the assumption that locative descriptions, and more generally the use of space, will exhibit widespread similarity across sign languages (Meier 2002; Talmy 2003; Sandler and Lillo-Martin 2006). Below we review the features associated with the structure of locative descriptions, and which are motivated by the iconicity assumptions. Taken together, these features form what we call the "canonical structure" of locative expressions.

3.1.1. The use of classifier predicates. Signed languages have been reported to use complex predicates (classifier predicates) ${ }^{7}$ to express spatial relations between entities. ${ }^{8}$ The handshape in these predicates represents the referent, typically by expressing information about salient characteristics of that referent. The position and movement of the hand(s) in sign space encode information about the location and motion of the referent(s) in the event space (Supalla 1982; Engberg-Pedersen 1993; Emmorey 2002; Zwitserlood 2003; and Perniss 2007).

In the example from ASL in (5) below, a classifier construction is shown in which a house is localized in sign space, followed by localization of a bicycle in sign space in relation to the house. In this example, there are two predicates: the first one connecting a referent (the Ground) with a particular locus in sign space (sign 2), and the second one (sign 4) connecting another 
referent (the Figure) with a particular locus in sign space in relation to the ground referent.

(5) ASL use of classifier predicates within a locative construction (Emmorey 2002: 87)

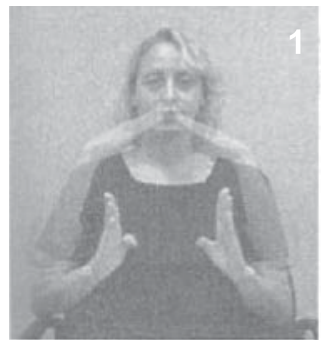

LH: HOUSE RH: HOUSE

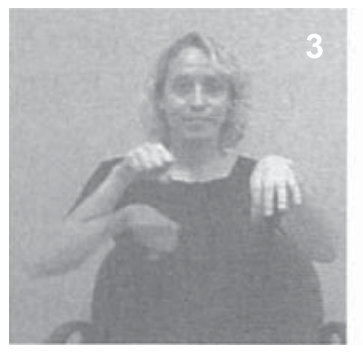

LH:

RH:

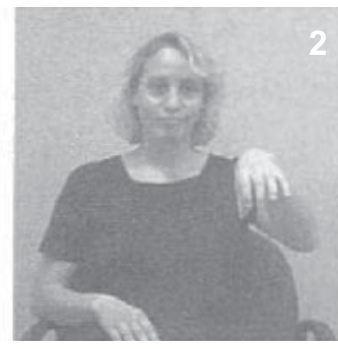

entity CL + locL----------

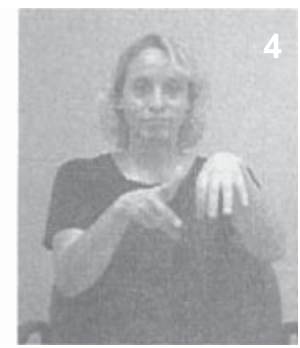

entity $\mathrm{CL}+$ locR

Literally: "A house is here, a bike is there, next to the house." Translation: "A bike is next to the house."

Three major types of classifiers are often distinguished in the sign language literature:

(i) Entity classifiers, which represent referents by encoding certain salient features of the referent in the shape of the hand (e.g., in ASL the classifier representing the house (bov) in (6) is generally used for bulky objects by representing bulky shape, and the classifier representing the bicycle ( membership of the referent in the class of vehicles);

(ii) Handling classifiers, which represent the handling or manipulation of referents, usually by an animate referent (e.g., a handshape in which the index finger and thumb touch (ean represent the handling of a small or thin entity, such as a sheet of paper or a single flower); 
(iii) Size and Shape Specifiers (SASSes) form another often mentioned type of classifier: these elements convey properties of the referent's size and shape by tracing the outline of the referent or by indicating its dimensional extensions, whereby the handshape contributes to the information about shape and size (see Brennan 1990; Engberg-Pedersen 1993; Liddell and Johnson 1987; Supalla 1982, 1986). In the example from German Sign Language (DGS) in (6), the signer uses SASSes in his description of the relative locations of a yellow and red cone next to each other. The signer not only traces the triangular shape of each cone, but also makes these signs at different locations in sign space. The second and last signs in this construction form SASS constructions that localize the cones; the last sign locates the red cone in relation (i.e., NEXTTO) to the yellow cone.

(6) DGS use of SASS classifier predicates in a locative construction (Perniss 2007: 114)
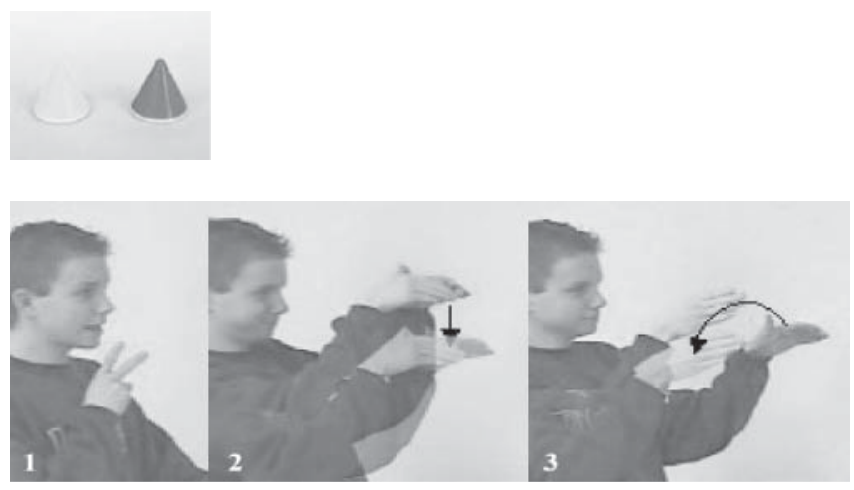

RH: YELLOW SASS(cone) + locL NEXT-TO:movR

LH: $\quad$ SASS(cone) + locL ----hold----------------------

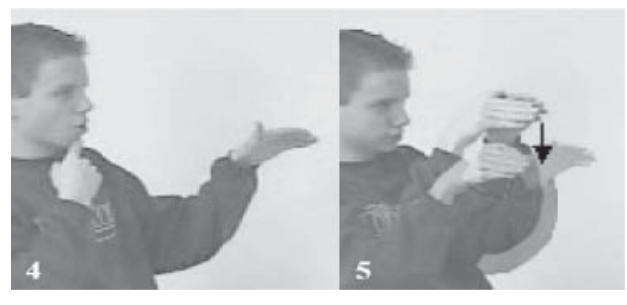

RH: RED SASS(cone)+locR

LH: ------------------- SASS(cone)+locR

Literally: "There is a yellow cone-shaped entity to the left, next to it on its right there is a red cone-shaped entity."

Translation: "There's a red cone next to a yellow cone." 
3.1.2. Relations between Figure and Ground. Spatial expressions in signed languages with classifier predicates appear to observe certain regularities. First, the referent noun is usually mentioned first, followed by the classifier predicate. Second, it is usually the case that the mention of the Ground (the bigger and/or backgrounded entity) comes previous to the mention of the Figure (the focal and/or smaller entity) in the locative construction, ${ }^{9}$ as in Example (5) where the house is mentioned before the bicycle. (See among others Emmorey [1996] for ASL; Morgan et al. [2008] for British Sign Language [BSL]; Engberg-Pederson [1993] for Danish Sign Language [DSL]; Perniss [2007] for DGS; and Miller [1994] for Quebec Sign Language [LSQ]). It has been suggested in the literature that this robust order is driven by a perception constraint (rather than a linguistic constraint) based on principles of Gestalt perception.

Thirdly, locative relations in signed languages need a prior and explicit mentioning of a localized Ground, in relation to which a Figure is localized (e.g., with the last signs in both of Examples (5) and (6)) (Emmorey 1996, 2002; Perniss 2007).

Finally, previous sign language research points out that the relative positioning of the Figure with respect to the Ground canonically includes the use of a simultaneous classifier construction. In locative classifier constructions, the manual articulators can simultaneously represent the Figure and Ground in space in relation to each other. A simultaneous classifier construction appears in Example (5), where the entity classifier representing the house is produced first and held in its location in sign space while the entity classifier representing the bicycle is localized next to it. (See Emmorey [1996]; Supalla [1982] for ASL; Engberg-Pederson [1993] for DSL; Perniss [2007] for DGS; Miller [1994] for LSQ; Morgan et al. [2008] for BSL; Chang et al. [2005] for Taiwan Sign Language [TSL]; Tang et al. [2007] for Hong Kong Sign Language [HKSL]). Note that the classifier predicates that form this simultaneous classifier construction are placed into sign space sequentially. It is also possible to achieve a simultaneous classifier construction by placing two classifier predicates into sign space at the same time. Though more research is needed on the temporal structuring of simultaneous classifier constructions, the placement of classifier predicates at the same time may be restricted to referents of the same type (cf. Perniss 2007).

3.1.3. Relational lexemes. It has been reported that instead of classifier predicates that allow for analogical representations, some signed languages can use "relational lexemes" (Arkk and Wilbur 2008) (also called "prepositions" in Emmorey [2002] or simply "relationals" in Arık [2009]) to indicate the spatial relation of entities with respect to each other. For example, the signer in the DGS example in (6) uses a relational lexeme next-to, in addition 
to the SASS construction, to locate the red cone next to the yellow one. However, "relational lexemes" do not seem to be the preferred means to express spatial relations, at least in ASL (Emmorey 2002). Although Arık and Wilbur (2008) mention the existence of relational lexemes in TID (glossed as 'in', 'on' and 'at'), they are not obligatory in spatial expressions.

Little research has been undertaken so far on the use of these lexemes and it is as yet unclear whether they can be used as the sole means of locative expression or are used in combination with other devices for expression of spatial relations, such as classifier predicates (see Johnston et al. 2007). Furthermore, no literature exists on the semantics or syntactic use of these lexemes or whether they show variation among different signed languages. Given the variation in this domain in spoken languages (Bowerman 1996), such variation in sign languages seems highly plausible.

\subsubsection{Summary: canonical structure and iconicity in signed languages.} Overall, locative constructions in signed languages have been characterized by the following features: the use of classifier predicates to locate referents; firstGround-then-Figure ordering; and the use of simultaneous classifier predicate constructions to express the spatial relations between Figure and Ground referents. These features have been attributed to the fact that they are driven by iconicity principles guiding spatial expression in the visual-spatial modality. Signers can create schematic correspondences between the hands in sign space and the real world locations of the entities being described on the basis of iconicity (Emmorey 1996; Aronoff et al. 2005). Below we explain further how each of these features, which together comprise the canonical structure of locative expressions, is associated with iconicity principles (see also Perniss [2007] on this view).

In classifier predicates, the handshape represents entities by encoding certain semantic and/or visual features of the entities, and the locations of the hands in sign space encode referent location by analogue mapping of an event space onto sign space. The independent use of the two hands as articulators affords another unique possibility of the visual-spatial modality: the use of simultaneous constructions (cf. Vermeerbergen et al. 2007). In particular, the simultaneous use of two classifier predicates allows the representation of two entities at the same time, such that the spatial relationship between them can be visually depicted. The use of relational lexemes (e.g., ON) is considered to be less preferred in the visual-spatial modality than the direct analogue representation of spatial relationships afforded by simultaneous classifier constructions (e.g., Emmorey 2002). Finally, it is assumed that the Ground object (as the bigger, backgrounded object) will be represented before the smaller, foregrounded Figure object. This order is also observed in drawing and may be a constraint of the visual-spatial mode of expression (Emmorey 1996, 2002). As defined by 
these properties, the use of a simultaneous classifier construction in locative descriptions is maximally iconic and driven by affordances of the visualspatial modality.

These modality-specific devices have given rise to typologically distinct structures in signed languages as compared to spoken languages in terms of locative expressions. The visual forms possible in signed languages allow multiple morphemes to be simultaneously present within one (complex) predicate (cf. "polymorphemic" structures [Engberg-Pederson 1993]). First of all, classifier predicates have been analyzed to contain at least two morphemes that can be simultaneously expressed: a classifier that represents the referent in the predicate (phonologically expressed by a particular handshape or a combination of handshapes) and a directed movement through sign space or a short movement directed towards a particular location in sign space (among others Supalla 1982, 1986; Engberg-Pederson 1993; Zwitserlood 2003). Second, in such structures the Ground can be represented simultaneously with the Figure. ${ }^{10}$ As such, signed languages pattern in typologically different ways than spoken languages where morphemes cannot be represented simultaneously, but only sequentially. ${ }^{11}$

In summary, locative expressions in signed languages are typically characterized by the mention of the Ground followed by a classifier predicate localizing the Ground, then the mention of the Figure followed by a classifier predicate in which the Figure is localized in relation to the (simultaneously represented) Ground. Because these structures appear to be a widespread phenomenon across signed languages, exhibiting the same regularities and expected to occur in locative expressions in view of the affordances of the modality, we take them to exemplify the "canonical structure" of locative expressions. Note that this term is in no way indicative of the frequency of use (on which very little information exists up to date [Perniss 2007]) on any given sign language where this structure has been reported. The canonical structure of locative expressions can be schematized as below:

[Ground NP] [Localization of Ground] -------------hold-

[Figure NP] [Localization of Figure]

Figure 1. The canonical structure of locative expressions in signed languages

\section{Locative expressions in TíD}

The purpose of this section is twofold. First, our aim is to report, for the first time, on locative expressions in TID and on the way in which they pattern in 
discourse contexts by giving a frequency distribution of different strategies used for the expression of locative relations in TID. In doing so we focus mainly on locative relations where the Figure and Ground are static and spatially coincident. Motion descriptions will be briefly mentioned, in particular in cases where we want to see if they radically differ from static ones or not. Second, we investigate to what extent the assumptions held in the previous signed language literature also hold for TİD, i.e., in what ways do TİD locative constructions share similarities with and show differences to the "canonical structures" described in previous research on spatial relations in signed languages.

\subsection{Background on TID}

The establishment of the first school for the Deaf in Turkey is dated to 1902 (Deringil 2002). In the early 20th century, there were only a few private Deaf schools in the country, in the cities of İzmir and Istanbul. Even though the use of a signed language in the period between 1500 and 1700 has been documented in the Ottoman Palace (Miles 2000), it is hard to attain evidence that contemporary TID is a continuation of the signed language used in the Palace. From 1953 until present, teaching of or in TiD has not been allowed in the schools; instead, oral teaching methods have been used. The Turkish Federation of the Deaf has been promoting signed communication among the Deaf population throughout the country in the Deaf clubs from its foundation in 1964. Although 2007 saw a new law passed in the Turkish Parliament to enable TíD teaching in schools, the application of this law awaits enough research to be conducted on TíD and education materials to be prepared based on that research.

To date, research on TID is still scant. Nevertheless, there exists a Webbased word (750 items) list (Özyürek et al. 2004), a short sketch of some historical and general characteristics of the language (Zeshan 2003), and an analysis of interrogative and negative constructions (Zeshan 2006). With regard to expressions of spatial relations, recent work by Arık (2008), Kubuş (2008), and Perniss and Özyürek (2008) confirms and investigates the use of classifier predicates in TID in the expression of spatial relations. This research has focused on the use of perspectives, frames of reference, and the types of classifier handshapes used in classifier predicates in TID, but provides no detailed information about the ordering of Figure and Ground or on the use of different strategies to encode locative relations in a discourse context. 


\section{A. Özyürek et al.}

\subsection{Methodology}

Two types of picture descriptions were used to elicit locative constructions from native TiD signers (i.e., deaf children born to deaf parents) in this study. One type was elicited by 28 photographs that contained different numbers of objects that were in various spatial relations to each other. These photographs contained one, two, three or four, or uncountable numbers of (i) cup(s) on a table or in a cupboard; (ii) boat(s) on water and beach; (iii) bird(s) on grass or street; (iv) pen(s) on a wooden surface and next to a notepad; (v) painting(s) on a wall and above chair(s); (vi) plate(s) on a table; and (vii) cows in a meadow (behind a fence). We will refer to this part of the study as "task-1". The second type of descriptions was elicited by 12 line drawings showing simple events, 11 of which depict animate and inanimate objects moving to or away from a location (the location thus functioning as a Ground for the movement), e.g., a man walking to a truck, and a baby crawling to a woman. One picture contained a topological spatial relation, viz. a boy standing on another boy's shoulders (task-2). ${ }^{12}$ Thus while task-1 elicited static spatial descriptions, task-2 elicited mostly motion descriptions.

The descriptions of these pictures and photographs were collected from fifteen TID users from the region of İzmir, Turkey, all of them native signers born to at least one (some signers to two) generations of Deaf families. For the purposes of this paper we analyzed descriptions of six of these signers for task-1 and four (who also did task-1) for task-2.

In task-1, each signer was presented with the photographs one by one on a laptop screen, and asked to describe each photograph to another TID user. The order of photographs was presented to the signers in a scrambled way in terms of number and identity of the objects (i.e., a photograph of one cup on a table, followed by a photograph of four pictures on a wall, followed by a photograph of two cows in a meadow, etc.). The signers did not know the whole repertoire of the all the photographs. This way, signers would not focus on the number or the objects as the most important information to be conveyed. The addressee was asked to identify the correct picture from a set of twenty pictures, based on the signer's description, and allowed to ask for clarification if necessary. (There were three different sets of twenty pictures; the addressee was given a new set of twenty pictures after nine or ten descriptions.) Task- 2 was basically the same, only in this task the addressee was to select the correct line drawing from a set of four, based on the signer's description of a stimulus item. (The addressee chose from a new set of four drawings for each description.) The purpose of including these tasks for the addressee was to make the communication purposeful for both interactants, as well as to make sure that the description was understood by the addressee. All addressees were Deaf, mostly native signers, although some had not acquired TiD from birth, but had started to 
acquire the language before they were 6 years of age. They are all considered highly proficient signers in their community. All addressees could pick the correct picture described by the signer (although in a few cases some clarification by the signer was needed).

\subsection{Findings}

In this paper, we focus primarily on descriptions of topological spatial relations between static objects. Thus, we report here only specific numerical counts from task-1 with specific examples. However, we checked for the generalizability of claims based on the static descriptions in task-1 with analysis of the results from task-2.

The 28 photographs in task- 1 gave rise to a total of 174 responses for six signers (three responses were incidentally not recorded; there were nine repeated, clarification responses). ${ }^{13}$ In 139 (80\%) of these responses a Figure was localized in relation to a Ground at least for one of the possible Figure items in the pictures. We took these 139 responses as a basis for further analysis of the structure of locative constructions. The twelve pictures in task-2 elicited a total of 48 responses for four subjects. In $32(66 \%)$ of these the Figure was localized in relation to a Ground. Although Figure and Ground were mentioned in the other responses, the Figure was not localized and thus we did not analyze these as locative expressions.

The signers generally used more than one strategy within one response to localize the Figure in relation to a Ground, in both tasks. Below we describe the strategies used in the locative constructions and their quantitative distribution.

4.3.1. Locative constructions by means of classifier predicates. In 94 $(67 \%)$ of the relevant responses at least one entity classifier predicate was used to localize the Figure in relation to a Ground. In only 4 (3\%) of these responses, however, the Ground was also localized with a classifier predicate. ${ }^{14}$ No handling classifiers occurred in the responses. ${ }^{15} \mathrm{~A}$ locative construction with an entity classifier predicate for the Figure and with a SASS (rather than with an entity classifier predicate) for localizing the Ground is illustrated in (7). 
1124 A. Özyürek et al.

(7)
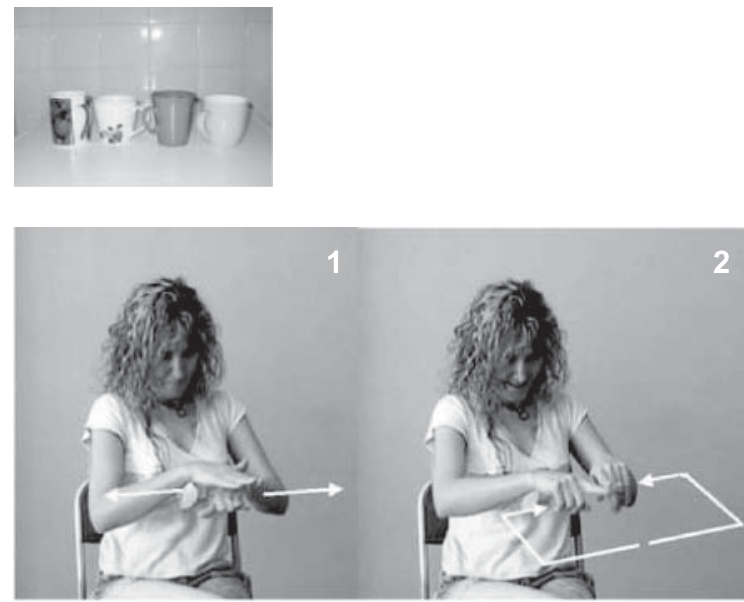

3

TID

LH: TABLE.locC

RH: TABLE.locC

SASS(square)

SASS(square)

FOUR

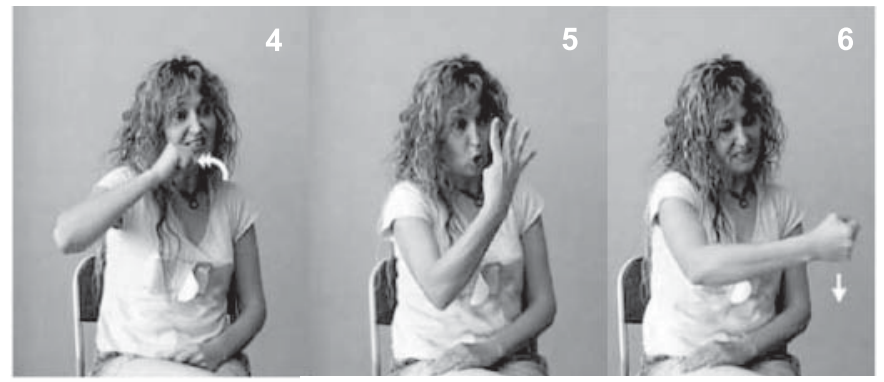

LH:

RH: CUP FOUR CL(cup).locC1

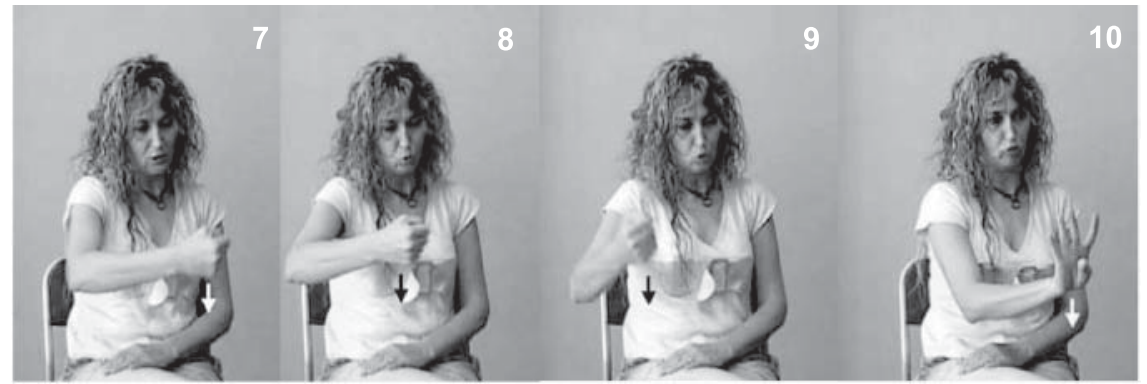

LH:

RH:CL(cup).locC2 CL(cup).locC3 CL(cup).locC4 $\quad$ NEXT-TO-4-LoC 
Literally: "There's a table here, it's square and there are 4 cups on it, next to each other. Four cups standing next to each other."

Translation: "There are four cups on the table, standing next to each other."

In this example the signer first introduces the Ground noun (for the table) and specifies the shape of the table, at a center location in sign space. Then she gives the number of objects in the picture and the Figure noun (for the cup) in signs 3 and $4 .{ }^{16}$ Next she uses entity classifier predicates to localize each cup (the classifier being formed by a fist $\mathbb{G}$ handshape) and a short downward movement to four different loci on the Ground. Through signs 6-9, she encodes the relation ON (in relation to the table), and in signs 7-9 she also encodes the relation NEXT-TO by choosing loci for each cup next to the previously localized cup.

In a few instances ( $7 \%$ of the responses), the TiD signers used SASSes to localize the Figure in relation to the Ground, after having introduced the Figure with a noun sign. An example is in (8), where the signer introduces the Ground (the wall), immediately localizing the wall in front of her, and then introduces the colorful paintings as Figures. The localization of paintings (as long narrow objects) is subsequently done by two SASSes signed simultaneously, one with each hand (sign 5). (Note that the signer later also uses two entity classifiers to localize both paintings next to each other on the wall, in sign 8).

(8)

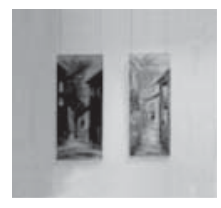

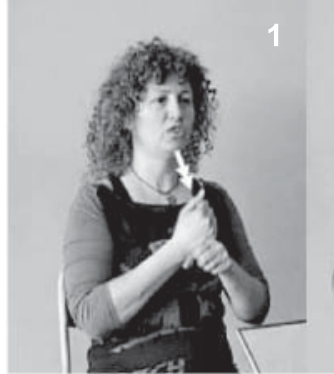

LH: STONE

RH: STONE

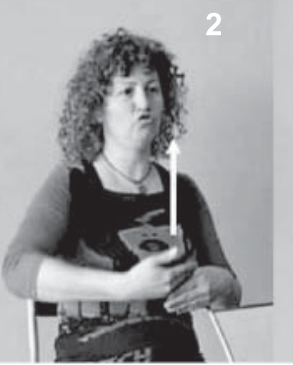

WALL-locC

WALL-locC

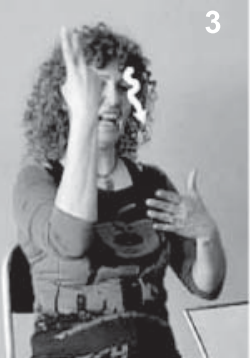

PAINTING 

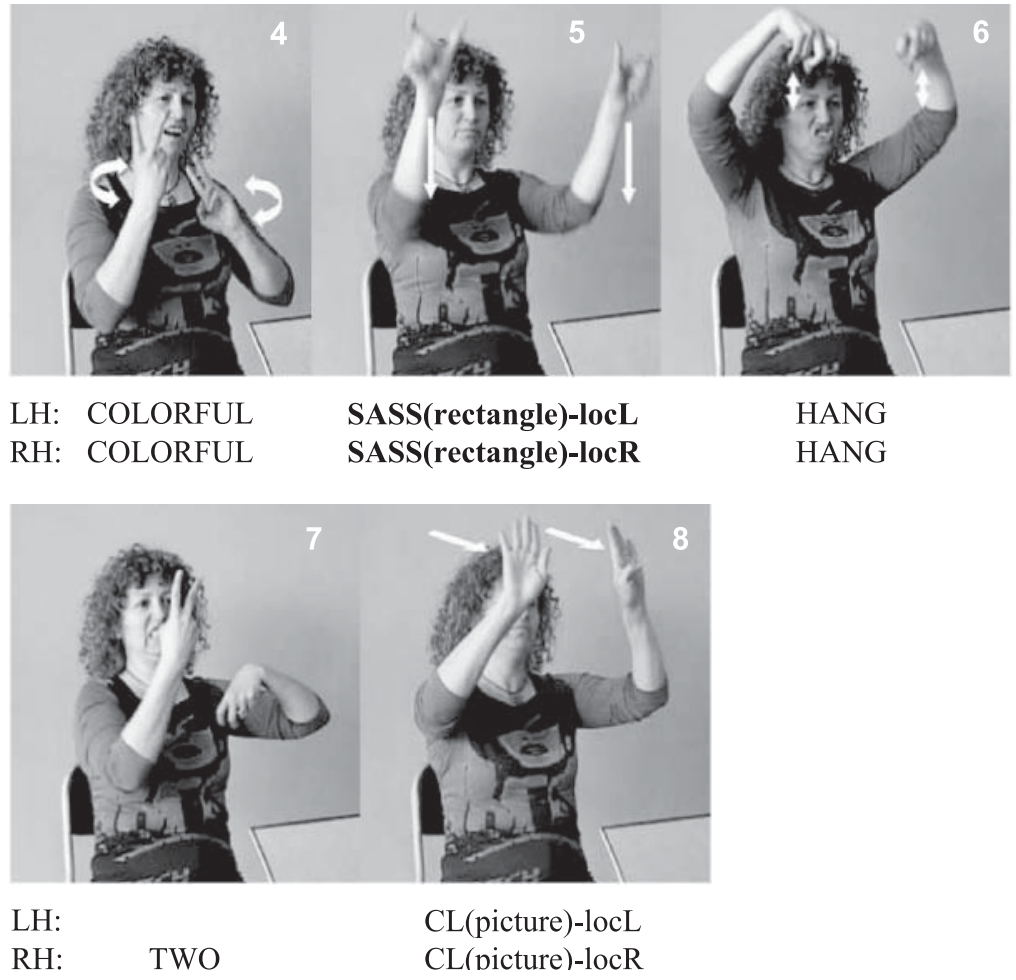

Literally: "There is a stone wall, and there are rectangular colorful paintings hanging next to each other on it. Two of them are next to each other on the wall."

Translation: "There are two colorful paintings hanging next to each other on a stone wall."

4.3.2. A locative predicate expressing a 'next-to' relationship. In addition to the use of classifier predicates, the TiD signers in our data sample also use a sign form that we analyze as a locative predicate which specifically encodes the semantic notion of 'next-to' for more than one object of the same kind. An example of this can be seen in sign 10 in Example (7) above. The signer holds four fingers upright to indicate that there are four cups next to each other. Alternative analyses of such forms (that occurred in 16 out of 104 responses for plural objects) might seem more obvious at first blush. One would be that these are instances of number incorporation in classifier predicates, where each referent is represented by a classifier (expressed with an extended finger), combined within one hand (see Supalla 1982, 1986 for ASL; Zwitser- 
lood 2003 for NGT). Another possibility would be that these are number signs localized in sign space, similar to direct localization of objects by articulation of a noun sign at a position in sign space (as explained in more detail in Section 4.3.3).

We argue that the first possibility can be ruled out, however, since the forms we encounter in our TID locative descriptions differ from classifier predicates with referent number incorporation in several important ways. Firstly and crucially, incorporation of referent number in the classifier predicate is reported to be possible only for referents that can be (singly) represented with an extended index finger (efil) (e.g., persons, pencils, and poles). The forms in our data, however, occur not only for objects that are typically represented with an extended index finger classifier, but also with other objects (e.g., cups, plates, or boats). This is particularly striking in Example (9) below, where sign 4 is used to represent three plates next to each other on the table. Plates, represented by a (2) classifier shape in other responses, reflecting their flat and round shape, have nothing in common with the long, thin shape of an extended finger. In cases where a single token of an object does not get represented by an extended index finger classifier, but where multiple tokens of the object do get represented by multiple extended fingers, the latter forms are arguably not classifier predicates with referent number incorporation.

As for the second possible analysis of these forms as localized number signs, the characteristics of numeral signs differ in several respects from the forms we are describing here. We thus argue that this analysis is also not correct. In number signs, the fingers point upwards and the palm of the hand faces toward the body (as in the number 'four' in signs 3 and 5 in Example (7) and in the number 'three' in sign 3 of Example (9)). However, in the forms under discussion, the orientation of the hand palm can be markedly different from that in the number signs, even when the finger orientation is consistent with that in the number signs. This is evident in sign 10 of Example (7), where the palm is facing outward. Moreover, it appears to be possible to reflect the dominant axis orientation (i.e., vertical or horizontal) of objects in the orientation of the hand in these forms, as the contrast between this sign form in Examples (7) and (9) illustrates. (Note that this is similar to the conveyance of position and posture information in classifier predicates). 
(9)
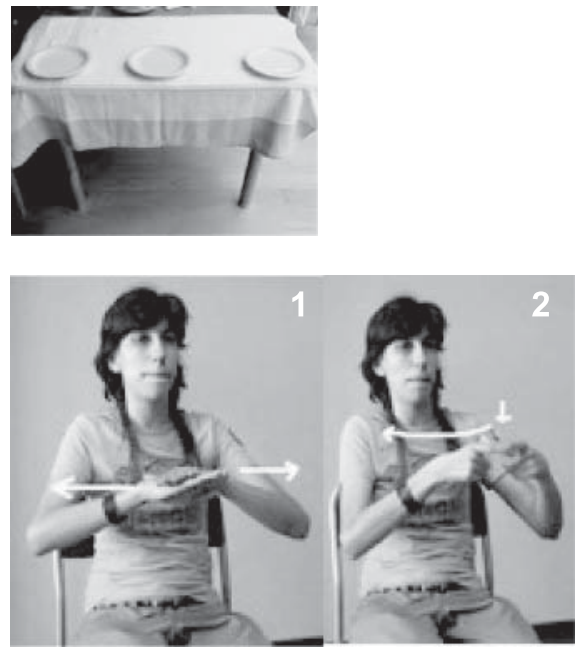

LH: TABLE

PLATE-pl-loc

RH: TABLE

PLATE-pl-loc

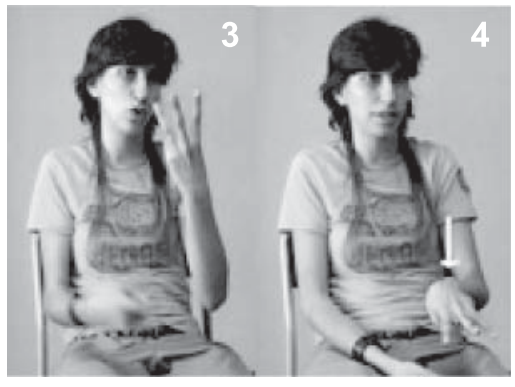

LH:

NEXT-TO(3)-loc

RH: THREE

NEXT-TO(3)-loc

Literally: "There is a table, and there are plates on the table, three of them, and they are next to each other."

Translation: "There is a table with three plates on it, next to each other on the table."

Another observation in our data with respect to this form is that it commonly (though not always) occurs together with classifier predicates, as a separate strategy for encoding locative information within a single picture description. We see this in Example (7) above, where the signer first uses a fist-shaped classifier ( $\mathrm{G}$ ) to represent cups at four distinct locations on the table (signs 6-9). 
The classifier predicates are followed by what we analyze as a 'next-to' form, in which four fingers are extended and pointing upwards (sign 10). The use of separate strategies suggests that each strategy, while displaying some redundancy of semantic information, contributes different focal information.

On the basis of the occurrence and shape of these sign forms as discussed here, we argue that they focus on the semantic aspect of next-toness in the spatial configuration, specifically encoding a side-by-side alignment of objects. The sign form does not provide visual-spatial information about the referent itself, as is generally the case in classifiers, including those with incorporation of referent number as they have been heretofore described. Furthermore, the referents' individual locations cannot be spatially modified, in terms of localizations by means of individual classifier predicates for each object, to convey a measure of metric distance information between objects. In addition to the relational side-by-side information, these signs provide information about the number of objects, as does a classifier predicate with number incorporation. However, the presence in the descriptions of the relevant number information in other signs (e.g., numerals) and constructions (e.g., the placement of multiple classifier predicates in relation to each other) suggests to us that the number information in these signs is not the primary, but rather a concomitant, semantic component.

In the TID data set analyzed for this paper, we have encountered 16 responses with this 'next-to' locative predicate ( $11 \%$ of all responses containing a locative expression $[n=139]$ and $15 \%$ of all relevant responses $[n=104]$ that include more than one object of the same type, e.g., two boats, three plates, four cows, etc.). All six signers in our TiD sample use the form, showing that it is not idiosyncratic. We propose that this form is used in TID as a locative predicate that highlights the side-by-side next-to relationship between multiple objects of the same type.

4.3.3. Locative constructions by means of localized lexical signs. Another way in which TID signers express locative relations is through the direct placement of the noun sign for the Figure at a particular location in sign space in relation to the location of the Ground. We encountered 27 responses (in the 139 relevant responses; 19\%) in which such sign localizations were used. This can be clearly seen in Example (10) in signs 5, 7, and 9. Here the signer localizes the boats on the sea by placing noun signs at different locations in sign space, rather than classifier predicates. 
(10)
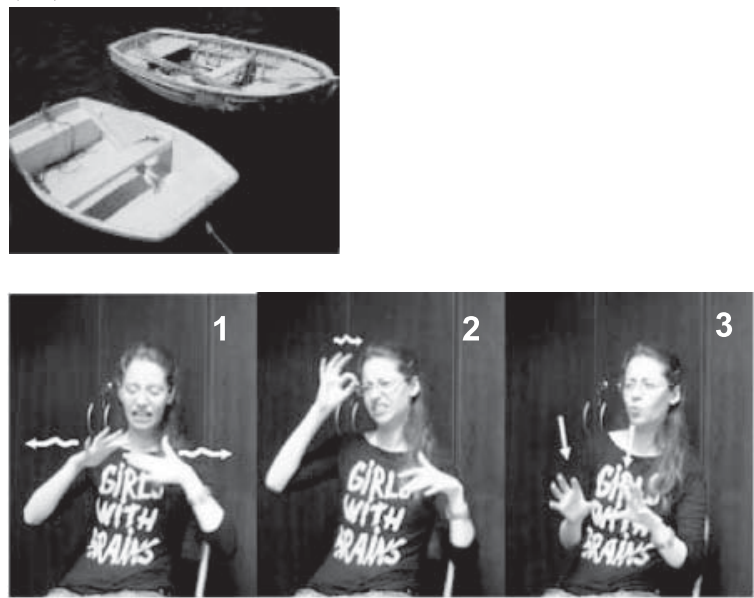

TID

LH: SEA+ locC $\mathrm{RH}: \mathrm{SEA}+$ locC

GREEN

DARK

DARK
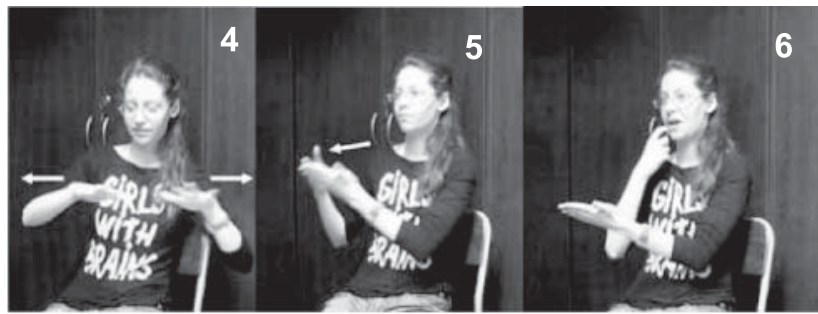

LH: SURFACE-locL RH: SURFACE-locL

BOAT-locR BOAT-locR -hold---------WHITE
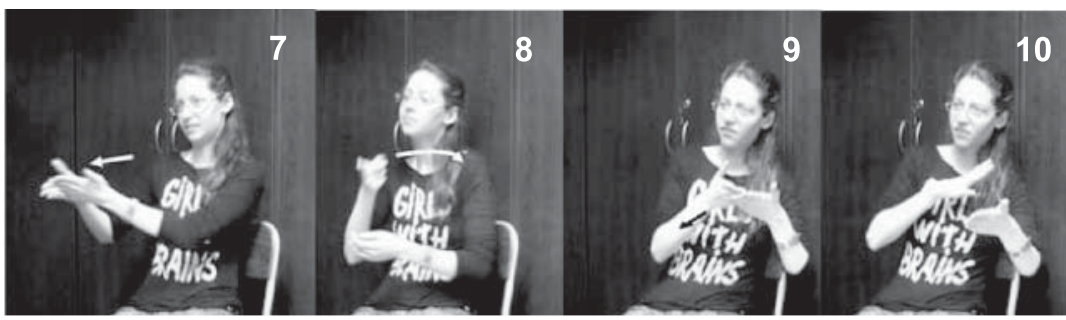

LH: BOAT-locR RH: BOAT-locR

OTHER

BOAT-locL -hold---------BOAT-locL

EXIST

Literally: "There is a sea with dark green surface, and there is a boat to the right on the water, a white boat to the right, and there is another boat to its left. There is such a situation"

Translation: "There is a dark green sea; there's a white boat to the right on the water and another boat to it's left." 
We also observed this strategy for the localization of cups, pictures, plates and in some cases for notepads. The signs that were localized in our data typically do not have a fixed place of articulation on the body, but are generally articulated in a default location, in front of the signer's body.

4.3.4. Relational lexemes. Our data contain a few signs that might be interpreted as "relational lexemes" (Arlk and Wilbur 2008). However, there were only few instances of such signs ( 1 in the 139 relevant responses). Because of their infrequency in this data set, we cannot make any claims about their status as yet.

4.3.5. The existential predicate. Finally, besides the various means discussed above, we also found a number of instances of the use of an existential predicate within a response (in 34 [24\%] out of the 139 relevant responses). This sign is shown in (11) above: the final sign glossed as EXIST. This existential predicate occurred after one or more locative strategies within a response (as can be seen in (10)).

4.3.6. Relations between Figure and Ground and the use of simultaneous constructions. As a next step, we investigated the order in which Figure and Ground were introduced in the signers' responses. In this respect, TiD patterns like other signed languages in that, in the majority of cases, a noun introducing the Ground precedes the mention of the Figure noun (in 130 (93\%) of the 139 relevant cases).

When we looked for simultaneous constructions expressing the relative positions of Figure and Ground, we found that TiD does not employ the "canonical" simultaneous classifier constructions mentioned in the literature. We found only two cases in 139 responses where a classifier representing the Ground was present during the localization of the Figure by a classifier predicate. However, even these two instances differ slightly from the canonical structure in that the Ground was not localized by a clearly distinct classifier predicate after the Ground sign had been introduced (as in (5)), Our data contained seven responses with simultaneous localization (e.g., as in the final frame in Example (8)) of entities. However, in our case these do not represent true Figure-Ground locative relations because (i) these constructions did not represent a bigger/backgrounded entity (Ground) and a smaller entity which is the focus of attention (Figure), but rather two instances of localization of a same referent (the Figure); and (ii) the localizations were not ordered sequentially (in which case the first localized referent could have formed the Ground for the second localized referent [see also Perniss 2007]).

The lack of simultaneous constructions can be seen in all of the examples from our data in (7) to (10). Though it is possible to represent the Ground in a 
simultaneous construction with the Figure in TID, it is certainly not the most frequent or preferred way of expressing locative expressions in TiD (we find only two instances of in our data set). In this respect, TiD does not exhibit the "canonical structure", as expected for signed languages from previous literature.

We also checked for occurrences of simultaneous constructions in task-2. Here, a simultaneous classifier construction was used in 7 (20\%) of 36 relevant responses where a Figure was localized in relation to the location of a Ground (i.e., the Ground, localized with a classifier predicate, was held while the Figure was localized). Thus, locative, nonsimultaneous constructions were also more frequent in the spatial motion descriptions. An example of such a description is shown in (11). One might have expected a "canonical structure" of the signer holding the classifier predicate representing the truck (the Ground) in its localized place, while the classifier predicate representing the walking man toward the truck is made. However, the classifier predicate for the Ground was usually dropped in our sample of spatial motion descriptions.
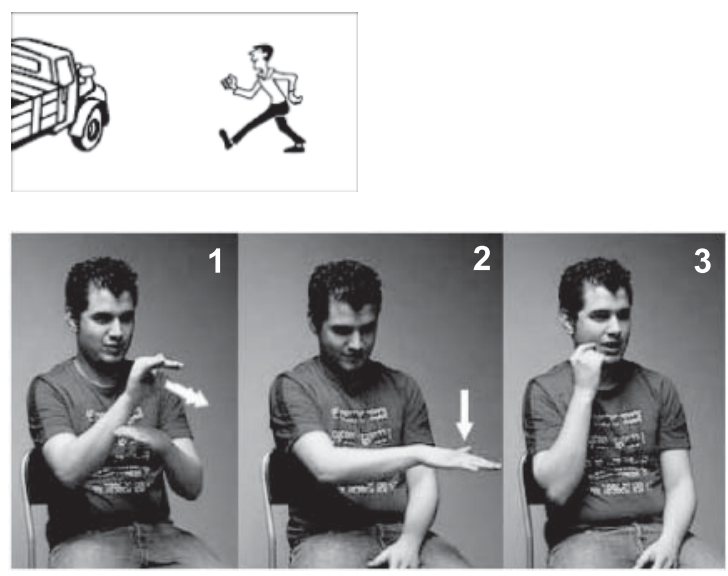

LH: TRUCK

RH: TRUCK

CL(truck)-locCR

MAN

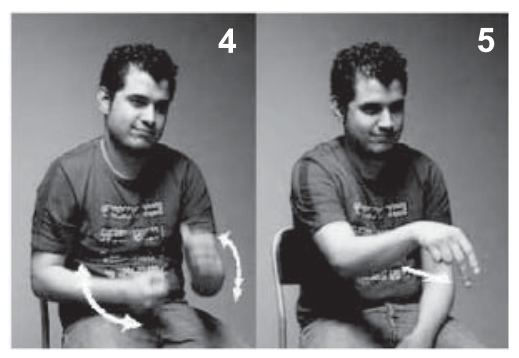

LH:WALK.BRISKLY

RH:WALK.BRISKLY CL(man)-WALK.TO-CR 
Literally: 'There's a truck here. A man walks up there.'

Translation: 'A man walks up to a truck.'

4.3.7. Summary of devices used in TiD locative constructions. As explained in detail above, the TID signers used mostly First-Ground-then-Figure order, in accordance with the canonical structure. They also used classifier predicates to locate the Figure (in almost half of the responses) in relation to the Ground. However, the Ground was expressed with a classifier predicate only in a few cases. Furthermore, the signers used devices other than classifier predicates in their locative expressions, such as locative predicates to encode several referents of the same kind in a next-to relation, immediate localization of noun signs, and SASSes. Importantly, we did not find simultaneous constructions to encode the relation between Figure and Ground. Table 1 below summarizes the frequency of these devices, collapsed over all six signers for task-1.

\section{TiD locative constructions compared to other signed languages}

Our analysis of locative constructions in TiD, based primarily on descriptions of static Figure-Ground relations and tentatively on motion descriptions, shows both similarities and differences between TID and other signed languages studied and reported to date. As for the similarities, TID exploits the affordances

Table 1. Frequency of different devices used to localize the Figure in relation to the Ground in the relevant responses for task-1

\begin{tabular}{|c|c|c|}
\hline Devices used locative expressions & Number of responses & $\%$ of responses $(\mathrm{N}=139)$ \\
\hline First-Ground-then-Figure order & 130 & 93 \\
\hline \multicolumn{3}{|l|}{ Location of Ground } \\
\hline Classifier predicates & 4 & 3 \\
\hline Placement of lexical signs/SASS ${ }^{17}$ & 135 & 97 \\
\hline \multicolumn{3}{|l|}{ Locating Figure in relation to Ground* } \\
\hline Classifier predicates & 94 & 67 \\
\hline Placement of lexical signs & 27 & 19 \\
\hline Locative predicate (next-to) & 16 & 11 \\
\hline Placement of SASS & 11 & 7 \\
\hline Relational lexemes & 1 & 1 \\
\hline Simultaneous constructions & 2 & 1 \\
\hline
\end{tabular}

* Note that the total number of responses for placing Figure are more than 139. This is due to the fact that each response could have more than one strategy. 
of the modality and prefers visually motivated structures to depict relations between a Figure and a Ground, as has been found for other sign languages. First of all, the most preferred strategy for Figure localization in our data was the use of classifier predicates: complex predicates that denote salient properties of referents and localize the Figure referents in relation to previously localized Ground referents in sign space. Second, relational lexemes (like on and BEHIND) are rarely used in the locative constructions in our data, as has also been reported for other sign languages. Third, the Ground referent was usually mentioned first, followed by mention of the Figure referent, similar to other signed languages.

However, TiD also exhibits features of locative constructions that have not been mentioned in the literature, and which may be language-specific devices which need to be confirmed by further research. Though classifier predicates are the most common way of locating referents in TiD, they are not the only device used to do so. TID uses a locative predicate to express next-to relations of referents of the same type, encoding neither shape properties of the referent nor the relations among the referents in an analogue way, as is typical of classifier predicates.

Second, TID signers can also directly localize Figure nouns (as well as Ground nouns) by localizing the Figure nouns in relation to Ground locations. This strategy seems to be constrained by phonological properties of the signs, i.e., the presence or absence of phonological specifications for a particular place of articulation. For example, "body-anchored" signs, which are specified for a location on the body, are unlikely to be localized. Again, further research is needed to exemplify this and to determine whether these constructions are subject to other kinds of restrictions. In addition, further research will show whether there are principles that guide the choice for this type of localization instead of localization by classifier predicates. The possibility of direct localization of noun signs in sign space has been reported in the literature for other sign languages and for different purposes (e.g., for possessives, Zeshan and Perniss 2008), and it is often encountered as an anecdotal mention lacking a specific example. There are no reports explicitly describing their use or function in spatial expressions.

Finally, simultaneous classifier constructions - which are portrayed as a prominent feature of the canonical locative construction in the literature - are not the preferred means to express the relation of a Figure with respect to a Ground in our TID data. Even though the signers usually localized the Ground, they did not do this with a classifier predicate, reducing the possibility of occurrence of simultaneous classifier constructions. We found similar patterns of absence of these constructions in our static spatial descriptions in task-1 as in the spatial motion descriptions in task-2. This is a rather striking result, which we will discuss in more detail below. 
There may be several reasons for the lack of simultaneous classifier constructions in our data - in contrast to many other signed languages as reported in the literature. First of all, it may be related to the types of Ground and Figure objects in our stimulus photographs: some of the spatial relations are very unmarked, default relationships (e.g., boats on the water), such that specifying the Ground may be considered unnecessary. However, this cannot be the main reason, since both tasks included a wide and nonoverlapping range of objects as Figures and Grounds (e.g., animate/inanimate; large/small; movable/ unmovable) as well as various spatial relations between them. Further research is needed to determine which types of relations, if any, may be more likely to be encoded by more "canonical" locative structures in TiD.

Second, as Perniss (2007) indicates, "violations" of the canonical simultaneous Figure-Ground representation may occur for articulatory reasons (e.g., when both hands are needed for representation of either the Ground or the Figure referent in a classifier construction). Indeed, in our data from task-1, some classifiers consist of a combination of two hands, such as a classifier for square objects ( $\left(\mathrm{S}_{\mathrm{C}}\right)$ representing paintings, and a classifier used to represent boats $\left({ }^{2}\right)$. However, most of the classifiers representing Figure referents in both task-1 and task-2 were one-handed (e.g., a truck as the Ground entity, represented with a fist hand ( $\left(\mathrm{G}^{3}\right)$ or a flat hand $(\mathrm{A})$ ), and a person as the Figure, represented with an upright entity classifier (d) or a 2-legged entity classifier $\left(h^{3}\right)$ ). Therefore, we do not think that the explanation for the nonpreference of simultaneous structures in TID lies in the type of stimuli or has to do with articulatory restrictions.

Instead, we argue that when TID signers do use simultaneous constructions (as in Example (12) below), it is to indicate a specific, nondefault, spatial relation between Figure and Ground. To describe a picture that depicts a boy standing on another boy's shoulders in task-2, four signers used a simultaneous classifier construction. This suggests that the nonsimultaneous indication of spatial locations, as is usually done in our data sample, might be preferred as a default if the exact spatial relation between both referents need not be explicitly mentioned and can be inferred. In contrast, a simultaneous construction can be used to depict the exact relation (i.e., ON in Example (12)) between a Figure and Ground (see also Section 6 for similar strategies used in spoken languages, such as Turkish). Another motivation to use simultaneous constructions could be to emphasize the relative orientation of two featured objects to each other (e.g., two people facing or following each other, Perniss 2007). More research, however, is necessary to exemplify under what conditions simultaneous classifier constructions are used in TID rather than the default nonsimultaneous ones. 
(12)
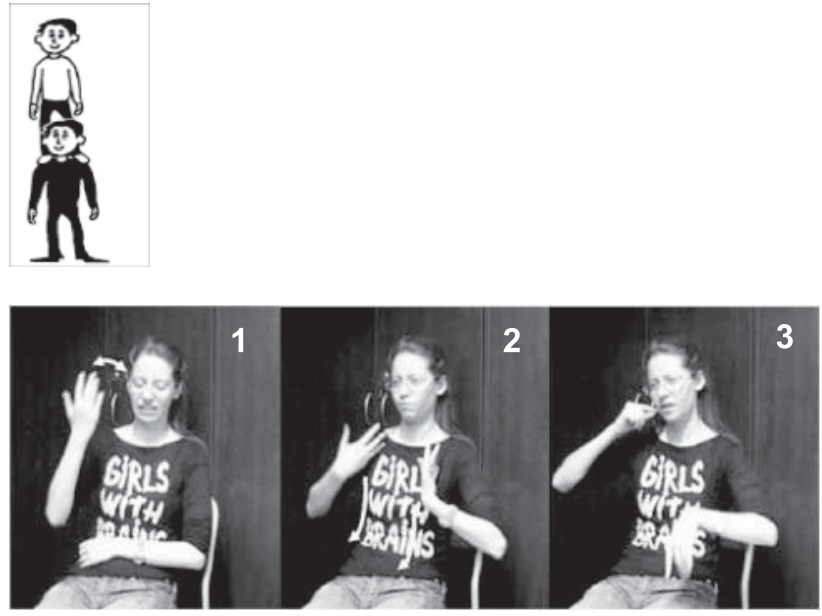

$T \dot{D}$

LH: BLACK

RH: BLACK

SWEATER

SWEATER

MAN
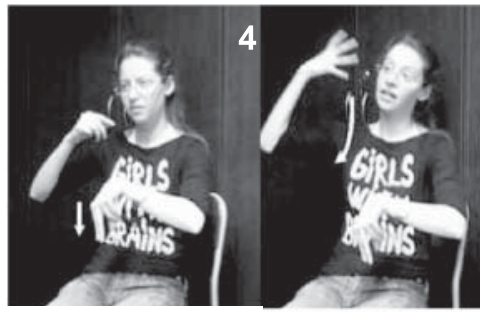

5

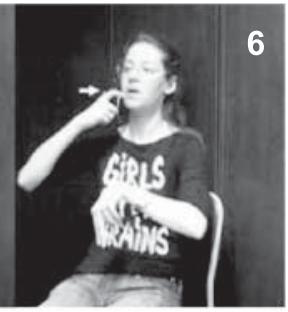

LH:

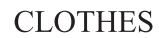

WHITE

RH: CL(legs) + locC

---hold-

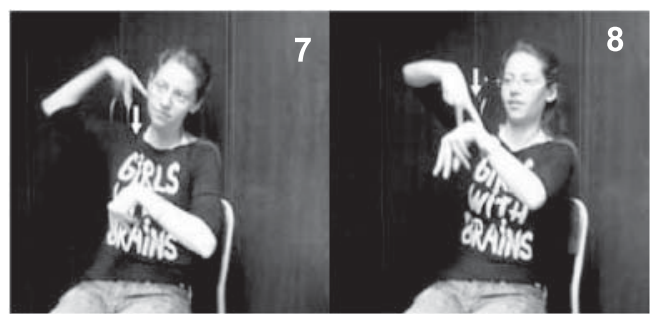

LH: CL(legs)-loc(shoulder) CL(legs)-loc(hand)

RH: ---hold

Literally: "A man wearing a black sweater is standing here and one with white clothes is standing on his shoulders, on top of him." Translation: "A man wearing white clothes is standing on the shoulders of a man with a black sweater." 
A third reason for the rare occurrence of the simultaneous constructions would be that intervening (two-handed) signs occurred between the classifier predicates for Ground and Figure, (especially since locative constructions were elicited in a discourse context, sometimes resulting in long responses). This discourse strategy could have motivated signers to drop the classifier predicate for the Ground and as a result reduce the uses of simultaneous constructions. ${ }^{18}$ However, in the descriptions in task- 1 , there were only very few cases $(2 \%$ of the responses) in which signers used a classifier predicate for the Ground object at all - another finding different from the canonical structure. In most cases, the signer used either a noun sign or a SASS that was localized immediately in sign space (Example 8, signs 1 and 2), rather than a classifier predicate; since the signers did not produce a classifier predicate for the Ground, they did not have the opportunity to drop it. Moreover, even in very short descriptions like (10) above we do not see that signers prefer simultaneous constructions. Nevertheless, our initial findings here illustrate the need for further research to determine the discourse uses of simultaneous constructions in more detail.

Finally, we found that an existential predicate was used together with different locative strategies in quite a few responses (see the last sign in (10)); a feature that is not part of the canonical structure. Existential predicates have been observed in a variety of signed languages (see Zeshan and Perniss [2008] for an overview) and their properties differ. Existential predicates appear to have a dual function in most of the signed languages in which they have been studied: they can indicate existentiality as well as possession. Arık and Wilbur (2008) mention that the existential predicate in TiD can, similarly, be used in possessive and existential constructions. Since the stimuli used in our study contain spatial situations and events with no possessive relations, an interpretation of the existential predicate as a possessive can be excluded in our data. The TiD existential predicate $c a n$ be used with locative constructions, but it is not necessary. Thus, it does not seem to add spatial or locative information to the construction. Rather, we argue that it is used to indicate a situation in which a locative construction is expressed. Thus, Example (11) could be literally translated as 'There exists a situation in which there is dark green sea, a white boat on the right on the water and another boat to its left.'

We conclude that locative expressions in TID, elicited in a discourse context and in a controlled setting, reveal structures other than those assumed by the canonical structure (see Figure 1 above) described in the literature for other signed languages. As far as we can see from our data, a number of different strategies are preferred in TID, as schematized in Figure 2. The Ground is introduced by a noun directly localized in space, followed by introduction of the Figure by a noun that is either directly or consecutively localized in relation to the location of the Ground, possibly followed by the existential predicate. Our 
[Ground NP + Localization] [Figure NP + Localization]

(EXIST)

or

[Figure NP][Localization of Figure]

Figure 2. The structure of locative expressions in TiD

findings suggest that there are at least three main strategies for localization of Figure and Ground: (i) localization by means of a noun sign or a SASS (both for Figure and Ground); (ii) localization by means of a classifier predicate (mostly for Figure); and (iii) localization by a locative next-to predicate (only for Figure). Further research on discourse corpora with more everyday use of TID or using comprehension measures should test whether and under what conditions this structure generalizes to other types of spatial relations, genres of usage, and types of stimuli.

\section{Comparison of locative descriptions in signed and spoken languages}

Even though both spoken and signed languages systematically and structurally encode the relations between Figure and Ground objects in spatial expressions, this appears to be done in radically different ways in the different modalities. These differences help us to understand what might be basic and common to all languages and what is modality-specific in spatial encoding.

At the beginning of this paper we laid out two main ways in which spoken languages of the world, as reported in most inclusive surveys of spatial language, encode relations between a Figure and a Ground: (i) by adpositions (spatial prepositions and postpositions) or ii) by locative or postural verbs (whereby combinations of these devices are also possible). Our general summary of sign language locative expressions, as well as the analysis of such expressions in one particular signed language, TiD, shows that signed languages in general have very different ways of encoding the relations between a Figure and a Ground than do spoken languages. The devices that are available to users of spoken languages are less visually specific than locations in sign space. They encode the spatial relation between objects in a categorical, visually degraded and abstract way. For example, an English speaker would typically say There are two cups are on the table to describe two cups on a table, and a Turkish speaker would say Masanın üstünde iki fincan var 'there are two cups are on top of the table'. The adpositions used in the English and Turkish expressions encode a general on relation between the cups and the table, but do not further encode on which part of the table the cups are, whether they are standing or lying next to each other, or how close the two cups are to each other. This would be possible, of course, but would require a long descrip- 
tion with many predicates. However, all this rich visual information between the entities can be mapped onto only one or two predicates in signed languages, as a result of the analogue and simultaneous aspects of the modality. Furthermore, the visual-spatial modality allows simultaneous, three-dimensional spatial structuring of information. Signed languages, thus, appear to take advantage of these affordances and, as a consequence, develop different, more visually specific and direct ways of linguistic encoding of spatial relations (Talmy 2003).

Some of the signed languages studied to date have been reported to have relational lexemes, but the users of these languages to do not prefer to use these abstract, categorical ways of encoding (as we also showed for TiD), but rather prefer the visually richer expressions. Adpositions could, then, be considered as modality-specific language structures, devised and suitable for spoken languages, where many relational semantic features need to be bundled and categorically represented (e.g., many types of ON relations between objects need to be represented and categorized under one spatial semantic category). In signed languages, in contrast, this semantic bundling and abstraction is not necessary and instead, in most cases, signers choose analogue mapping of referents to sign space - in line with the predictions of the canonical structures.

On the surface, signed languages seem to be rather similar to spoken languages that encode locative relations in the verb (e.g., Ewe) and more specifically to those that use postural verbs (e.g., Tzeltal). In postural verbs, the orientation of the Figure (e.g., horizontal, vertical) is encoded. Similarly, we saw that the orientation of Figure referents is expressed (combined with location) in the next-to locative predicates in TiD. Posture information can also be encoded in classifier predicates in signed languages (see also Supalla 1982; Zwitserlood 2003; Perniss 2007). However, in signed languages, different pieces of spatial information can be encoded simultaneously in one predicate, such as orientation and/or posture with shape, location and/or next-to relations. This is not the case for spoken languages, even for those that use verbs encoding location or posture.

On the other hand, it is also important to stress that in spite of these modalityspecific differences between signed and spoken languages, they also share similarities in the way locative expressions are structured. One similarity, we would like to argue, might concern the ways of encoding general versus more specific spatial relations between the referents. For example, languages that use locative case markers as well as spatial nouns (like Turkish), encode a general spatial relation between the two entities when only the general locative case marker $-d a$ ' at' is used. The spatial relations are encoded more specifically if a spatial noun is used to which a locative case marker is attached (see (2a) and (2b) in Section 2). It is argued (Lestrade in prep.) that in languages that employ several types of adpositions and spatial case, adpositions are used to 
express more fine-grained locative relations, like we find in spoken Turkish. Our study of TiD reveals similar strategies. First, we argue that TiD signers use nonsimultaneous constructions when they encode a more general, default spatial relation between the Figure and the Ground, e.g., by representing Figure and Ground at particular locations with respect to each other in sign space. In this way, the relative positioning of the Figure and Ground is encoded, but no further information is given about the relative orientations of the objects, nor is the exact configuration of the topological relation depicted that could have been possible with a simultaneous constructions. However, when signers use simultaneous classifier constructions (as in (12)), more detailed information on a specific, more marked spatial relation between the two objects, including their posture, is encoded. Second, our analysis of TID shows that signed languages can also use strategies such as locative predicates that express next-to relations, which categorize spatial relations and use these semantic bundles in addition to analogue mapping by means of classifier predicates. This appears to be more similar to spoken languages, where forms are discrete and bundle together certain semantic aspects. Encoding of spatial relations in signed languages may exhibit semantic and pragmatic constraints similar to some spoken languages in spite of differences in modality.

\section{Conclusion}

In summary, this paper shows that spoken and signed languages exhibit differences in the way in which spatial relations are structured and specifically in how locative relations are expressed. Nevertheless, even though signed languages can and do make use of the spatial affordances of the manual-visual modality, this does not necessarily result in similar ways of linguistic structuring of space in across sign languages, as has been claimed in the literature. Our initial analysis of TID shows that different signed languages can develop different linguistic structures and can show variation in the use of such structures (see also Nyst [2007] for the lack of entity classifier predicates in Adamorobe Sign Language in Ghana), even if they use the same modality. However, more research on a variety of signed languages is needed, which looks at patterning at the discourse level, as well as single elicited utterances, before we can decide whether the "noncanonical" structures we see in TID are languagespecific patterns or whether they would also be encountered in other signed languages when similar discourse contexts are taken into account.

A general linguistic theory of spatial relations, and specifically of locative expressions, needs to take all structures that might arise in both modalities into account before it can generalize over the human language faculty. 


\section{Appendix: A note on gloss representation}

The gloss conventions for the examples from spoken languages are as follows:

ABS: absolutive case

LOC: locative case

POss: possessive

GEN: genitive case

DAT: dative case

PREP: preposition

$3 \mathrm{p}$ : third person

Traditionally, signs are represented by glosses (labels for signs in a spoken language) for lack of an accepted orthography for sign languages and due to the difficulty of representation and the space-consuming character of pictures or photographs of signs. Although we present examples in photographs (i.e., stills from the recorded movies), we adhere to this tradition by glossing them.

We use the following conventions:

The actions of the left hand and right hand are indicated by LH and RH respectively. If a sign is made with two hands, its gloss is notated for both LH and RH.

CL: classifier

CL(cup): classifier representing a cup

SASS: Size and Shape Specifier

loc: location in sign space

mov: movement through sign space

L, R, C, CR, C1, . . : Various locations in sign space: Left, Right, Center, Center-Right, Center $1, \ldots$

Loc1, 2, . . : Various locations in sign space

---hold-----: the hand is held still for the duration indicated by the hyphens

$+:$ simultaneous articulation of components in one sign

\section{Notes}

1. This research was funded by Dutch Science Foundation (NWO), VIDI grant awarded to Ozyurek, Max Planck Institute for Psycholinguistics and a Marie Curie fellowship (\#41886) awarded to Perniss. We would like to thank Marloes van der Goot for technical assistance and archiving of the data, Hasan Huseyin Yilmaz for the TiD translations, İzmir Sağırları Koruma ve Kalkındırma Derneği, Izmir, Hatay, Turkey (Izmir Deaf Association) and its members for their help in conducting this study, and to Connie de Vos for her comments and 
anonymous reviewers on the manuscript. This research is supported by the NWO-VIDI scheme grant given to A. Özyürek.

Asli Özyürek and Inge Zwitserlood are affiliated with the Radboud University Nijmegen, Center for Language Studies and Max Planck Institute for Psycholinguistics; Pamela Perniss is affiliated with Radboud University Nijmegen, Center for Language Studies, Max Planck Institute for Psycholinguistics and University College London, DCAL Research Centre. Correspondence address: Asli Özyürek, Max Planck Institute for Psycholinguistics, P. O. Box 310, 6500 AH Nijmegen, the Netherlands. E-mail: Asli.Ozyurek@mpi.nl.

2. Note that the type of relations encoded by locative expressions in languages is not limited to these categories. For example locative expressions also encode frame of reference relations between entities (e.g., the cat is in front of the car) or those that are not necessarily in a Figure-Ground relation.

3. The use of a capital " $D$ " in "Deaf" is generally used to make a distinction between the medical diagnosis of a person not being able to hear (deaf) and people's consideration of themselves as belonging to a cultural/linguistic minority of Deaf people (Deaf).

4. It is also possible that locative case markers appear on the verb.

5. The glosses are explained in the Appendix. Some of the glosses in the examples taken from the literature have been adapted slightly for purposes of consistency.

6. It is not impossible for spoken languages also to have simultaneous ordering of information, e.g., in the expression of tone or co-speech gestures that are an integral part of language.

7. The term "classifier predicate" is one of various terms for the same phenomenon in signed languages. Other terms are polycomponentional signs, polymorphemic predicates, verbs of motion and location and depicting verbs to mention a few. The status and structure has been extensively debated. The diversity of terms notwithstanding, it is generally agreed that these signs are morphologically complex and contain at least a meaningful hand configuration and movement. For an elaborate discussion of the phenomenon, see Zwitserlood (forthcoming). In this paper, we will use the term 'classifier predicate'.

8. See among others Supalla $(1982,1986)$ for classifiers in ASL, Schembri (2002) for Auslan, Brennan (1990) for British Sign Language, Perniss (2007) for German Sign Language, Engberg-Pedersen (1993) for Danish Sign Language, Meir (2001) for Israeli Sign Language, Cuxac (2000) for French Sign Language, Wallin (1996) for Swedish Sign Language, Zwitserlood (2003) for Sign Language of the Netherlands, Chang et al. (2005) for Taiwan Sign Language).

9. In many spoken languages Figure is usually mentioned before the Ground, as in (1)-(4).

10. The full morphological structure of these simultaneous constructions is as yet unclear. While many studies of classifier predicates do not give detailed morphological accounts, some researchers consider a simultaneous classifier construction to be one complex classifier predicate (e.g., Sandler and Lillo-Martin 2006: 90-91, Tang et al. 2007), whereas others argue that each hand in a simultaneous classifier construction articulates a separate (complex) predicate (e.g., Engberg-Pedersen 2004: 85; Zwitserlood 2003: 221-222).

11. Even though Sandler and Lillo-Martin (2006) suggest that polymorphemic structures of signed languages resemble template morphology in Arabic languages, this resemblance has not been demonstrated in encoding semantic components of spatial relations but mostly in domains of time and aspect marking

12. The stimuli can be obtained from the authors.

13. A response is the signing from the moment that the signer's hands move from a rest position (e.g., in the lap) to the moment where the hands move back into a rest position. The responses were not segmented into sentences or clauses for lack of clear criteria for such segmentation.

14. In the majority of responses the Ground referents were either expressed by noun signs placed in space and/or SASSes. We are still analyzing which one of these categories each sign belongs to in our data set. 
15. In the case of a classifier for cups ( $\left(\mathbb{B}^{3}\right)$ one can argue that by shape it could have been a handling classifier (indicating holding a cup's handle). However the closed fist handshape can not be used in holding a cup but rather represents the cup as an entity that looks like the cup. Furthermore there was no agent holding the cups in our pictures. Thus concluded that this classifier should be analyzed as an entity classifier, like all other classifiers occurring in the data set.

16. Between signs 4 and 5 the signer gives information about each single cup. Due to space limitations, we do not show these signs in Example (7).

17. Although the localization of the Ground signs was clear in some responses because the signs were articulated to the left or right of the signer (where in citation form they are made in front of the signer), many localizations of the Ground noun were in neutral space-in front of the signer. In the cases where the location of the sign was inconclusive, we nevertheless inferred a localization of the Ground noun if the Figure was clearly localized in relation to it (e.g., a classifier predicate for cup was placed on top of the place used for localizing the Ground).

18. An intervening two-handed sign occurring between localization of the Ground and localization of the Figure with classifier predicates does not necessarily hinder a canonical simultaneous classifier construction; signers can resume the Ground classifier construction after a two-handed sign, or articulate a two-handed sign with one hand only (as shown in (5)).

\section{References}

Ameka, Felix K. \& James Essegbey. 2006. Elements of the grammar of space in Ewe. In Stephen C. Levinson \& David P. Wilkins, Grammars of space. Explorations in cognitive diversity, 359399. Cambridge: Cambridge University Press.

Arık, Engin. 2008. Locative constructions in Turkish Sign Language (TID). In Ronice Müller de Quadros (ed.), Sign languages: Spinning and unraveling the past, present and future: Forty five papers and three posters from the 9th theoretical issues in sign language research conference (ISLR9), Florianopolis, Brazil, December 2006, 15-31. Petrópolis/RJ. Brazil: Editora Arara Azul.

Arık, Engin. 2009. Spatial language: Insights from signed and spoken languages. Purdue: Purdue University dissertation.

Arrk, Engin \& Ronnie Wilbur. 2008. Locatives, existentials, and possessives in Turkish Sign Language (TID). Poster presented at the 82nd Annual Meeting of the Linguistic Society of America, Chicago, IL, January 3-6.

Aronoff, Mark, Irit Meir \& Wendy Sandler. 2005. The paradox of sign language morphology. Language 81(2). 301-344.

Bowerman, Melissa. 1996. Learning how to structure space for language: A cross-linguistic perspective. In Paul Bloom, Mary A. Peterson, Lynn Nadel \& Merrill F. Garrett (eds.), Language and space, 385-436. Cambridge, MA: MIT Press.

Brennan, Mary. 1990. Word formation in British Sign Language. Stockholm: University of Stockholm.

Chang, Jung-hsing, Shiou-fen Su \& James H-Y. Tai. 2005. Classifier predicates reanalyzed, with special reference to Taiwan Sign Language. Language and Linguistics 6(2). 247-278.

Cuxax, Christian. 2000. La langue des signes Française: les voies de l'iconicité [French Sign Language: the ways of iconicity]. Paris: Ophrys.

Deringil, Selim (2002) Iktidarın sembolleri ve idioloji: II. Abdülhamid Dönemi (1876-1909) [The symbols of the power and ideology: The era of II. Abdülhamid]. Istanbul: YKY.

Emmorey, Karen. 1996. The confluence of space and language in signed languages. In Paul Bloom, Mary A. Peterson, Lynn Nadel \& Merrill F. Garrett (eds.), Language and space, 171209. Cambridge, MA: MIT Press. 
Emmorey, Karen. 2002. Language, cognition, and the brain. Insights from sign language research. Mahwah, NJ: Lawrence Erlbaum.

Engberg-Pedersen, Elisabeth. 1993. Space in Danish Sign Language: The semantics and morphosyntax of the use of space in a visual language. Hamburg: Signum.

Engberg-Pedersen, Elisabeth. 1994. Some simultaneous constructions in Danish Sign Language. In Mary Brennan \& Graham Turner (eds.) Word order issues in sign language: Working Papers, 73-88. Durham: International Sign Linguistics Association.

Grinevald, Colette. 2006. The expression of static location in a typological perspective. In Maya Hickmann \& Stéphane Robert (eds.), Space in languages. Linguistic systems and cognitive categories, 29-58. Amsterdam: John Benjamins.

Johnston, Trevor, Myriam Vermeerbergen, Adam Schembri \& Lorraine Leeson. 2007. 'Real data are messy': Considering cross-linguistic analysis of constituent ordering in Auslan, VGT, and ISL. In Pamela M. Perniss, Roland Pfau \& Markus Steinbach (eds.), Visible variation. Comparative studies on sign language structure (Trends in Linguistics: Studies and Monographs 188), 163-205. Berlin \& New York: Mouton de Gruyter.

Klima, Edward S. \& Ursula Bellugi. 1979. The signs of language. Cambridge, MA: Harvard University Press.

Kubuş, Okan (2008). An analysis of Turkish Sign Language (TID) phonology and morphology. Ankara: The Middle East Technical University MA thesis.

Lestrade, Sander. In prep. The space of case. Nijmegen: Radboud University Nijmegen dissertation.

Levinson, Stephen C. \& David P. Wilkins (eds.). 2006. Grammars of space. Explorations in cognitive diversity. Cambridge: Cambridge University Press.

Liddell, Scott K. \& Robert E. Johnson. 1987. An analysis of spatial-locative predicates in American Sign Language. Paper presented at the Fourth International Symposium on Sign Language Research, Lappeenranta, Finland, July 15-19.

Meier, Richard P. 2002. Why different, why the same? Explaining effects and non-effects of modality upon linguistic structure in sign and speech. In Richard Meier, Kearsy Cormier \& David Quinto-Pozos (eds.), Modality and structure in signed and spoken languages, 1-26. Cambridge: Cambridge University Press.

Meier, Richard P, Kearsy Cormier \& David Quinto-Pozos. 2002. Modality and structure in signed and spoken languages. Cambridge, Cambridge University Press.

Meir, Irit. 2001. Verb classifiers as noun incorporation in Israeli Sign Language. In Geert Booij \& Jaap van Marle (eds.) Yearbook of morphology 1999, 299-319. Dordrecht: Kluwer.

Miles, Mike. 2000. Signing in the seraglio: Mutes, dwarfs and jesters at the Ottoman court 15001700. Disability \& Society 15(1). 115-134.

Miller, Christopher (1994). Simultaneous constructions in Quebec Sign Language. In Mary Brennan \& Graham H. Turner (eds.), Word-order issues in sign language, 89-112. Durham: The International Sign Linguistics Association.

Morgan, Gary, Rosalind Herman, Isabelle Barriere \& Bencie Woll. 2008. The onset and mastery of spatial language in children acquiring British Sign Language. Cognitive Development 23. $1-19$.

Nyst, Victoria. 2007. A descriptive analysis of Adamorobe Sign Language (Ghana). Utrecht: Netherlands Graduate School of Linguistics (LOT) dissertation.

Özyürek, Asl1, Deniz İlkbaşaran \& Engin Arık. 2004. Türk işaret dili/Turkish sign language. http:// turkisaretdili.ku.edu.tr (accessed 15 May 2010).

Perniss, Pamela. 2007. Space and iconicity in German Sign Language (DGS). Nijmegen: MPI Series in Psycholinguistics 45 dissertation.

Perniss, Pamela, Roland Pfau \& Markus Steinbach. 2007. Visible variation: Cross-linguistic studies on sign language structure. Berlin \& New York: Mouton de Gruyter. 
Perniss, Pamela \& Aslı Özyürek. 2008. Representations of action, motion, and location in sign space: A comparison of German (DGS) and Turkish (TID) Sign Language narratives. In Josep Quer (ed.), Signs of the time: Selected papers from TISLR 8, 353-378. Hamburg: Signum.

Poizner, Howard, Edward Klima \& Ursula Bellugi. 1987. What the hands reveal about the brain. Cambridge, MA: MIT Press.

Sandler, Wendy \& Diane Lillo-Martin. 2006. Sign language and linguistic universals. Cambridge: Cambridge University Press.

Schembri, Adam. 2001. Issues in the analysis of polycomponential verbs in Australian Sign Language (AUSLAN). Sydney: University of Sydney dissertation.

Supalla, Ted R. 1982. Structure and acquisition of verbs of motion and location in American Sign Language. San Diego: University of California San Diego dissertation.

Supalla, Ted R. 1986. The classifier system in American Sign Language. In Colette Craig (ed.), Noun classes and categorization, 181-214. Amsterdam \& Philadelphia: John Benjamins.

Talmy, Leonard. 1985. Lexicalization patterns: Semantic structure in lexical forms. In Timothy Shopen (ed.), Language typology and syntactic description: Grammatical categories and the lexicon, 57-149. Cambridge: Cambridge University Press.

Talmy, Leonard. 2003. Spatial structuring in spoken language and its relation to that in signed language. In Karen Emmorey (ed.), Perspectives on classifiers in signed languages, 169-195. Mahwah, NJ: Lawrence Erlbaum.

Tang, Gladys, Felix Sze \& Scholastica Lam. 2007. Acquisition of simultaneous constructions by deaf children of Hong Kong Sign Language. In Myriam Vermeerbergen, Lorraine Leeson \& Onno Crasborn (eds.), Simultaneity in signed languages, 283-316. Amsterdam \& Philadelphia: John Benjamins.

Vermeerbergen, Myriam, Lorraine Leeson \& Onno Crasborn (eds.). 2007. Simultaneity in signed languages. Amsterdam \& Philadelphia: John Benjamins.

Wallin, Lars. 1996. Polysynthetic signs in Swedish Sign Language. Stockholm: University of Stockholm.

Woll, Bencie. 2003. Modality, universality and the similarities among sign languages: An historical perspective. In Anne Baker, Beppie van den Bogaerde \& Onno Crasborn (eds.), Cross-linguistic perspectives in sign language research, 119-131. Hamburg: Signum.

Zeshan, Ulrike. 2003. Aspects of Türk Işaret Dili (Turkish Sign Language). Sign Language and Linguistics 6(1). 43-75.

Zeshan, Ulrike. 2006. Interrogative and negative constructions in sign languages. Nijmegen: Ishara Press.

Zeshan, Ulrike \& Pamela Perniss. 2008. Possessive and existential constructions in sign languages. Nijmegen: Ishara Press.

Zwitserlood, Inge. 2003. Classifying hand configurations in Nederlandse Gebarentaal (Sign Language of the Netherlands). Utrecht: University of Utrecht dissertation.

Zwitserlood, Inge. Forthcoming. Classifiers: Meaning in the hand. In Roland Pfau, Markus Steinbach \& Bencie Woll (eds.), Sign language: An international handbook. Berlin \& New York: Mouton de Gruyter. 